\title{
Climatic Changes of Thermal Conditions in the Pacific Subarctic at the Modern Stage of Global Warming
}

\author{
I. D. Rostov ${ }^{凶}$, E. V. Dmitrieva, N. I. Rudykh \\ V. I. Il'ichev Pacific Oceanological Institute, Far Eastern Branch of Russian Academy of Sciences, \\ Vladivostok, Russian Federation \\ 凶rostov@poi.dvo.ru
}

Purpose. The study is aimed at identifying the regional features of the surface air temperature in the coastal zone and over the Pacific Ocean (to the north of $40^{\circ} \mathrm{N}$ ) manifested as a result of global climate changes at the turn of the XX-XXI centuries, and at assessing their trends and possible causal relationships with the processes in the atmosphere and on the ocean surface.

Methods and Results. Based on the Global Meteorological Network and NOAA reanalysis data, the regional features of interannual oscillations of the surface air temperature and their relationship with variations in the fields of pressure, wind and water temperature on the ocean surface, and with climate indices over the past 4 decades were identified. In order to determine the temperature field spatial-temporal structure and to zone the water area according to the features of climate changes, the methods of cluster, correlation analysis and the apparatus of empirical orthogonal functions were used. The results obtained made it possible to characterize the degree of heterogeneity of the studied area response to the ongoing global changes, to identify different domains and to assess quantitatively the warming rate in these water areas.

Conclusions. The tendencies of modern warming are manifested in the trends of interannual air temperature variability, on the average, by $\sim 0.20^{\circ} \mathrm{C} / 10$ years in the subarctic, and indicate significant regional differences (1.5-2 times) in the ongoing changes. In the west of the region, the warming rate is higher than in the east, where the temperature trends are minimal or statistically insignificant. In the warm period of a year, their values are higher than those in the cold period. The alternation phases of the warm and cold periods are consistent with the variation tendencies in the characteristics both of the atmospheric action centers and various climatic parameters. The corresponding correlations are most widely manifested in variations in the empirical orthogonal functions modes of the $\mathrm{H}_{500}$ geopotential field, and the PDO, NP, SOI, PTW, AD and EP/NP indices. Stable anomalies and trends of the ocean surface temperature in the North Atlantic also play an important role in formation of the $T_{a}$ anomalies in the western subarctic.

Keywords: Pacific Ocean, subarctic, coastal zone, modern climatic changes, regional features, air temperature, warming trends, climatic parameters, correlations

Acknowledgments: The work was carried out within the framework of the state task to POI FEB of RAS on theme No. 0271-2019-0003. State registration number is AAAA-A17-117030110042-2. The authors are thankful both to the software developers for opportunity of using the climatic data posted on the NOAA sites, and to the reviewer for his constructive remarks.

For citation: Rostov, I.D., Dmitrieva, E.V. and Rudykh, N.I., 2021. Climatic Changes of Thermal Conditions in the Pacific Subarctic at the Modern Stage of Global Warming. Physical Oceanography, [e-journal] 28(2), pp. 149-164. doi:10.22449/1573-160X-2021-2-149-164

DOI: $10.22449 / 1573-160 X-2021-2-149-164$

(C) I. D. Rostov, E. V. Dmitrieva, N. I. Rudykh, 2021

(C) Physical Oceanography, 2021

\section{Introduction}

Modern warming to varying degrees is expressed over oceans and continents in almost all climatic zones. The last four decades are characterized by rapid changes in climatic conditions, manifested in various geospheres with significant 
spatial (from region to region) and temporal (from season to season, from year to year) heterogeneity [1-4]. As a result of planetary changes and the shift in the climate regime since the late 1970s, a phase of increasing positive trends in water and air temperature anomalies is observed. And the recent years have become the warmest in the history of observations [1, 5-6]. Moreover, even slow climatic changes occurring over large areas have long-term and large-scale consequences affecting various spheres of the economy and ecology [4, 7, 8]. Global causes, regional peculiarities and consequences of the ongoing climatic changes are diverse and are widely discussed. It is noted that one of the indicators of these changes are the tendencies of warming in the lower troposphere and significant cooling in the lower stratosphere against the background of a weakening of the zonal component of wind speed $[6,9,10]$. The increase in the greenhouse gas concentration in the atmosphere continues, being a key driver of climate change $[4,5]$. In the northern Pacific Ocean, a shift in the climatic regime of the late 1970s is well expressed in the characteristics of interannual oscillations of large-scale anomalies of meteorological and oceanographic parameters, the state of the atmosphere action centers (AAC), as well as indicators of heat and energy exchange between the ocean and the atmosphere [3, 4, 8, 11-14]. An important role in the formation of such anomalies belongs to the energy-active zone of the ocean and atmosphere (EAZO) of the northwestern Pacific Ocean and the continuation region of the Kuroshio, associated with increased heat and moisture fluxes from the ocean surface in the torrid zone and temperate latitudes and contributes to the strengthening of tropical and extratropical cyclones, advection of heat to high latitudes and its redistribution between various regions [15-20].

Warming in the continental regions generally goes more rapidly than in the oceanic ones and is more pronounced in the Northern Hemisphere (NH). In recent decades, the trend of air temperature increase in $\left(T_{a}\right)$ over the $\mathrm{NH}$ continents was estimated at $\sim 0.3^{\circ} \mathrm{C} / 10$ years, and in the northern Pacific Ocean $\sim 0.2^{\circ} \mathrm{C} / 10$ years, where warming is more pronounced in the summer-autumn season. In the Southern Hemisphere, these values are much less. In this case, the $T_{a}$ trend value increases in the direction from low latitudes to higher ones, and the interannual variation of seasonal temperatures in each of the regions has its own peculiarities $[1,2,4,9]$. Thus, according to observations at coastal meteorological stations (MS), the positive trend value in the mean annual air temperature in the seas of the eastern sector of the Arctic over the past 40 years ranged from 0.7 to $1.5^{\circ} \mathrm{C} / 10$ years [21], which is significantly higher than the corresponding estimates for the marginal seas of the western Pacific Ocean, such as the Sea of Okhotsk $\left(0.3-0.4^{\circ} \mathrm{C} / 10\right.$ years $)$, Sea of Japan $\left(0.2-0.3^{\circ} \mathrm{C} / 10\right.$ years), Yellow, East China and South China seas $\left(0.1-0.2^{\circ} \mathrm{C} / 10\right.$ years) [22]. At the same time, until 2014 near the northwestern coast of America, there were no the stable tendencies to warming $[1,23]$, which was replaced by a period of growth of positive anomalies in water and air temperatures in recent years [6].

In the present paper, the regional features of interannual changes in surface air temperature in the Pacific subarctic over the past four decades, manifested as a result of planetary changes and a shift in the climatic regime at the turn of the $20^{\text {th }}-21^{\text {st }}$ centuries, are specified. 
The considered water area is a vast zone of the subarctic cyclonic gyre to the north of $40^{\circ} \mathrm{N}$, occupied by the waters of the subarctic structure and its modifications [24, 25]. The great length, structural and circulation features of the atmosphere and ocean in this area determine the noticeable differences in the most important climatic indicators in the latitudinal and meridional directions in all seasons of the year. Weather and climatic conditions are determined here mainly by the interaction of three main baric formations that are seasonal AACs: the Aleutian minimum (Aleutian depression), the North Pacific (Hawaiian) High and the Siberian winter anticyclone, which determine the wind field structure and the state of the upper layer of the ocean. Climatic changes occurring in the northern Pacific Ocean and the Pacific subarctic, through circulation mechanisms in the atmosphere and regional AACs, are closely related to similar phenomena in other regions [2, 26-28] and influence the ongoing global processes, being an important regulator of interdecadal climatic fluctuations [29-31].

\section{Data and Methods}

To analyze interannual changes in thermal conditions, monitored homogeneous data sets of air temperature $\left(T_{a c}\right)$ observations at 59 weather stations of the GHCN-M (V3) NOAA global climate network (https://www.ncdc.noaa.gov/ghcnm/v3.php) for 1978-2018 were used. The grid data of reanalysis ( $T_{a}-N C E P / N C A R$ Reanalysis-1) [32], fields of pressure, wind and heat fluxes on the ocean surface, as well as climatic indices (CI) taking into account the seasonality of their action: PDO, AMO, SOI, PTW, NP, WP, PNA and $E P / N P$, was used in the present study [22]. The considered CIs have a clear geographic reference and a definite physical interpretation ([2], https://climatedataguide.ucar.edu/climate-data). The listed data was obtained from its developer website (https://www.esrl.noaa.gov/psd/): NOAA/OAR/ESRL PSD, Boulder, Colorado, USA and from the sites NOAA/NCEI/CPC https://www.nodc.noaa.gov/ and https://www.cpc.ncep.noaa.gov/. Regional indices of the Aleutian $(A l)$ and Asian $(A D)$ depressions were calculated from the surface pressure value.

To ensure the comparability of quantitative estimates with the results obtained for other geographic regions [21, 22], a unified method of processing and analyzing the data used was applied. The analysis of the interannual changes structure in the fields of air temperature, water on the ocean surface (SST) and atmospheric pressure was carried out using the method of decomposing the anomalies of these fields into principal components, or empirical orthogonal functions (EOF). The method provides the ability to extract the most important information from observational data arrays by decreasing the dimension and highlighting the principal components or modes [33]. Taking into account the duration of the summer and winter monsoons in the northwestern Pacific Ocean and the intraannual cycle of $T_{a}$, the conditionally warm (June - September) and conditionally cold (November - March) seasons (periods) of the year were distinguished. Trends were estimated for a time series that includes mean annual values of the variables and their anomalies $(\Delta)$, defined as the deviation from the average for all years of the 30-year period of 1984-2013. 
In the present work, the 95\% significance level of time series trends was calculated by the Student's $t$-test using effective degrees of freedom [33], where the time series length $(N)$ was divided by the integral estimate $(T)$ obtained from the autocorrelation function. Calculation of the correlation coefficients was carried out by the "bootstrap" method [33]. To determine the correlation coefficient $R$ of two time series, 5,000 pseudo-samples were generated, and generalized estimates of the correlation coefficient, standard deviation and standard error were calculated. These values were used to determine the 95\% significance level of $R$ according to the Student's $t$-test.

Using $T_{a}$ reanalysis data and optimal interpolation of water temperature on the ocean surface (as a more inertial characteristic) for the same years (NOAA OI SST V2) [34] from https://www.esrl.noaa.gov/psd/ by cluster methods analysis for three main components ${ }^{1}$ in the Pacific subarctic, six relatively isolated regions were identified: the western part of the Bering Sea (WBS), the Alaska-Aleutian (AA), the western subarctic (WSA), the transition domain (TD) or the mixing zone [25], the eastern subarctic (ESA) and coastal region (CR) (Fig. 1). Further, by simple averaging of station or grid data within the boundaries of each region, the long-term variation of air and water temperatures in the coastal zone and in open water areas was calculated. The relative error in calculating the linear trend when grouping station data was 3-6\%. $T_{a}$ and SST oscillations in each of the identified areas are characterized by very close correlations $-R>0.9$, and the relationship of temperature variations between areas is significantly lower than the relationship between them in the region center with any other point within the region. Note that the Sea of Okhotsk water area is not included in this scheme, since it was already considered before [22].

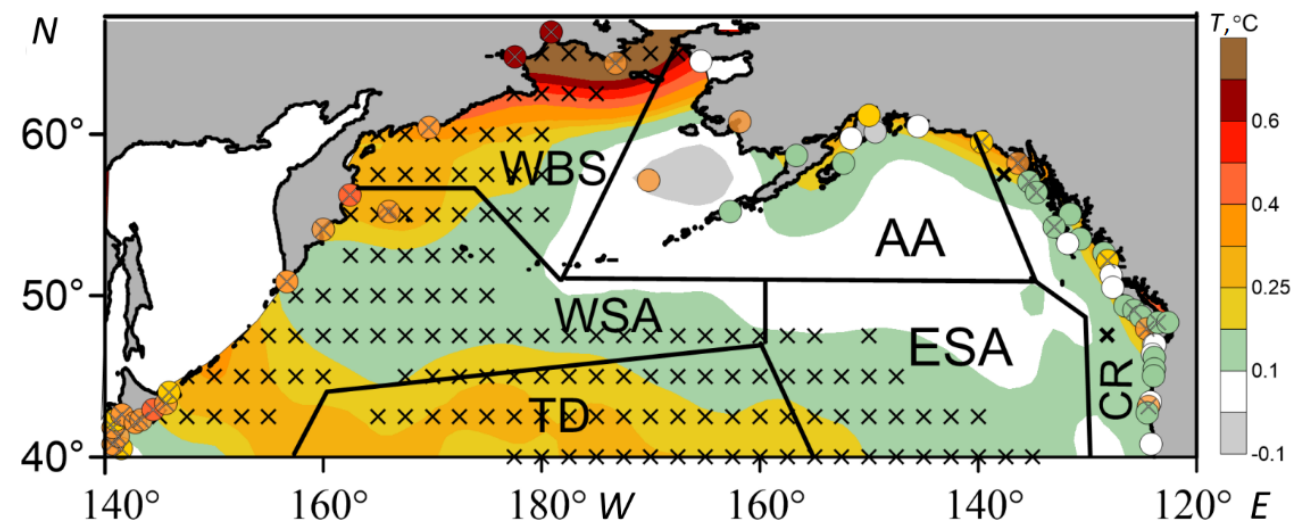

F i g. 1. Scheme of location of the meteorological stations and the identified domains, the values of the annual average air temperature trends for $1978-2018\left({ }^{\circ} \mathrm{C} / 10\right.$ years $)$ based on the meteorological stations and reanalysis data. Crosses mark the grid points and the stations where the trends are statistically significant at the $95 \%$ level

\footnotetext{
${ }^{1}$ Ding, C. and He, X., 2004. K-Means Clustering via Principal Component Analysis. In: Association for Computing Machinery, 2004. ICML'04: Proceedings of the Twenty-First International Conference on Machine Learning. New York, NY, United States : Association for Computing Machinery, p. 29. doi:10.1145/1015330.1015408
} 


\section{Features of spatial and interannual variability of air temperature}

The location of the identified areas (Fig. 1) generally agrees with the natural physical and geographical zones of the subarctic region and the schemes of spatial features of the structural and circulation characteristics of its waters [24, 25]. Climatic differences of the selected areas are manifested when comparing both generalized estimates of average and extreme values of air temperature oscillations, and trends of corresponding temperature changes (Fig. 1). Years with extreme values of $T_{a}$ are roughly consistent with the corresponding extrema in the course of mean annual temperatures in the entire $\mathrm{NH}$, calculated by the authors using the NCEP/NCAR Reanalysis-1 data and reflecting the global warming trend. Quantitative assessments of the trends of the changes taking place on average for the year and in individual seasons are given in Table 1.

Table 1

Trends of interannual changes of the air temperature anomalies at the meteorological stations $\left(T_{a c}\right)$ and in the identified domains based on the reanalysis data $\left(T_{a}\right)$ for the observation period 1978-2018

\begin{tabular}{l|c|c|c|c|c}
\hline \multicolumn{1}{c|}{ Area } & Parameter & $b$ & $T r$ & $b_{\mathrm{T}}$ & $b_{\mathrm{x}}$ \\
\hline \multirow{2}{*}{ WBS } & $T_{a c}$ & $\mathbf{0 . 4 3}$ & 1.8 & $\mathbf{0 . 4 5}$ & 0.34 \\
& $T_{a}$ & $\mathbf{0 . 3 8}$ & 1.6 & $\mathbf{0 . 4 5}$ & 0.28 \\
\hline \multirow{2}{*}{ AA } & $T_{a c}$ & 0.12 & 0.5 & $\mathbf{0 . 1 7}$ & 0.02 \\
& $T_{a}$ & 0.09 & 0.4 & 0.14 & 0.0 \\
\hline \multirow{2}{*}{ WSA } & $T_{a c}$ & $\mathbf{0 . 2 9}$ & 1.2 & $\mathbf{0 . 3 1}$ & $\mathbf{0 . 2 8}$ \\
& $T_{a}$ & $\mathbf{0 . 1 9}$ & 0.8 & $\mathbf{0 . 2 6}$ & $\mathbf{0 . 1 7}$ \\
\hline \multirow{2}{*}{ ED } & $T_{a}$ & $\mathbf{0 . 2 4}$ & 1.0 & $\mathbf{0 . 3 0}$ & $\mathbf{0 . 2 2}$ \\
\hline \multirow{2}{*}{ CR } & $T_{a}$ & 0.14 & 0.6 & $\mathbf{0 . 2 1}$ & 0.05 \\
\hline Whole area & $T_{a c}$ & 0.15 & 0.6 & $\mathbf{0 . 1 6}$ & 0.14 \\
\hline
\end{tabular}

$\mathrm{N}$ o t e. $b$ is the linear trend slope coefficient, ${ }^{\circ} \mathrm{C}$ for 10 years; $t r$ is the 40 -year trend, ${ }^{\circ} \mathrm{C} ; b_{\mathrm{w}}, b_{\mathrm{c}}$ are the values of $b$ for warm and cold seasons. Here and in the other tables, statistically significant (95\%) estimates are highlighted in bold.

Warming trends are expressed in all areas of the region under consideration, except for AA and CR. In the western part of the subarctic zone, the $b$ values are noticeably higher than in the eastern one, where the $T_{a}$ and $T_{a c}$ trends are either minimal or statistically insignificant, which is consistent with the results of studies carried out in other years [1, 6, 8, 13, 23]. In the northwestern Bering Sea (WBS area, Fig. 1), both according to observations at the MS and according to reanalysis, the highest $b$ values are noted $\left(0.6^{\circ} \mathrm{C} / 10\right.$ years and $0.9^{\circ} \mathrm{C} / 10$ years, respectively) comparable with the estimates for the seas of the eastern Arctic sector for the same period [21]. Over the past 40 years, in the coastal-island zone of the western subarctic region (WBS and WSA areas), the mean annual air temperature has increased by $1.2-1.8^{\circ} \mathrm{C}$, and in adjacent sea areas by $0.8-1.6^{\circ} \mathrm{C}$. In the transition PHYSICAL OCEANOGRAPHY VOL. 28 ISS. 1 (2021) 
domain (TD) and the eastern subarctic (ESA), the warming trends corresponded to a moderate $T_{a}$ increase by $0.6-1.0^{\circ} \mathrm{C}$, while in the northeast and east (AA and CR) this growth was minimal, about $0.4-0.7^{\circ} \mathrm{C}$. In general, according to the reanalysis data, the value of the mean annual $T_{a}$ trend over the entire Pacific subarctic water area was about $0.20^{\circ} \mathrm{C} / 10$ years, which corresponds to a warming of $0.8^{\circ} \mathrm{C}$ over the past 40 years. As a rule, in the warm season, these values are higher than in the cold one (Table 1).

Changes in the mean annual $T_{a}$, as well as its anomalies $\left(\Delta T_{a}\right)$ and cumulative anomalies $\left(\sum T_{a}\right)$, in some areas vary considerably in the amplitude and synchronism of oscillations, especially in the western and eastern parts of the subarctic zone (Fig. 2, $b, f$ and 2, $d, i, j$ ). The closest correlations of $\Delta T_{a}$ variations $(R=0.7-0.8)$ were found between separate adjacent areas: WSA/TD and $\mathrm{AA} / \mathrm{CR}$.

Oscillations in the $\Delta T_{a}$ time course with 2-7 year interval are specific for the ocean and the atmosphere. They can be associated with the El Niño impact with a time shift of several months against the background of a general growth trend in $T_{a}[4,35,36]$. Integral curves of cumulative anomalies correspond to separate phases of alternation of warm and cold periods, noted earlier in different years of observations [1, 3, 8], which are consistent with changes in regional climatic index (CI) and the AAC state [2, 9, 22]. Individual extrema on the curves (Fig. 2) emphasize the heterogeneous nature of the warming process in space and time. For example, in the eastern part of the subarctic zone, the maximums of 2003-2005 and 2014-2016 are expressed (Fig. 2, c, i, k), which, according to the authors' estimates (according to NCEP/NCAR Reanalysis-1 data), are consistent with the deepening period (up to 995 mbar), eastward displacement and localization of the Aleutian depression area in winter and weakening of the Hawaiian High in summer. Moreover, from the late 1970s to the late 1990s. In the Alaska-Aleutian region (AA), in contrast to other regions of the Pacific subarctic zone, there was a tendency for a continuous increase in the sum of positive $T_{a}$ anomalies (Fig. 2, $d$ ), which is also associated with the peculiarity of interannual changes in the atmospheric pressure field in the tropical and extratropical zones of the Pacific Ocean, the state of regional AAC and El Niño [12, 37]. According to our estimates and the data published, in winter the time intervals under consideration corresponded to the periods of the greatest exacerbation of the pressure gradient between the Aleutian depression and the Siberian High, in summer - to the warm (positive) phase of the $P D O$ index $[17,28,38]$. 

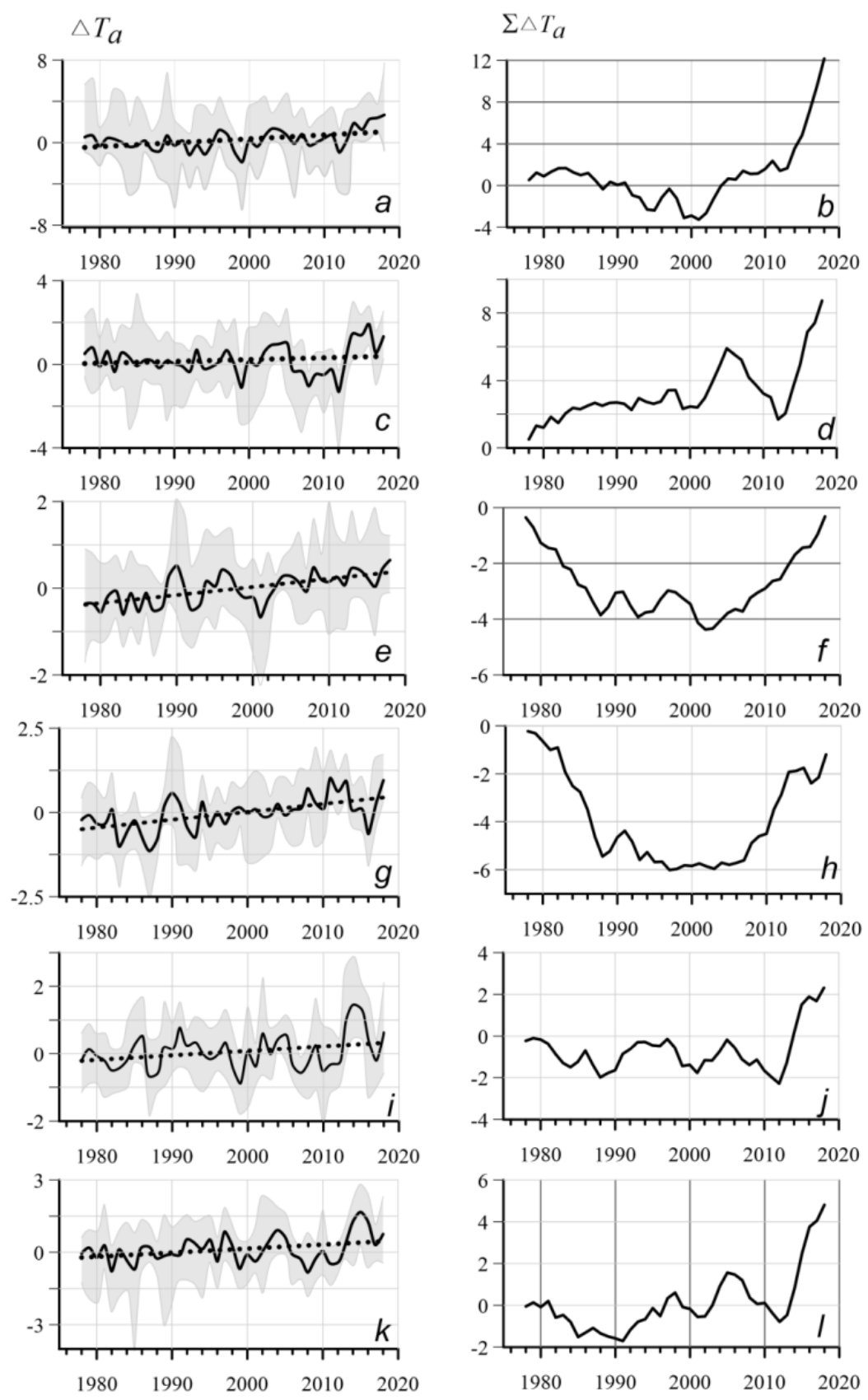

F i g. 2. Interannual variability of the annual average air temperature anomalies $\Delta T_{a}$ and the cumulative anomalies $\Sigma \Delta T_{a}$ in the identified domains: WBS $(a, b)$; AA $(c, d)$; WSA $(e, f)$; TD $(g$, $h)$; ESA $(i, j)$; CR $(k, l)$. The range of oscillations, mean values in the region (bold lines) and linear trend (dotted lines) are shown

According to the data of coastal meteorological stations, the features of the dynamics of the interannual variation of air temperature anomalies in the eastern and western sectors differ significantly, and the alternation phases of 
warmer and colder years are well coordinated only within each of these sectors (Fig. 3). At the same time, the phases of $\Delta T_{a c}$ changes on the MS are consistent with the corresponding phases of oscillations of the SST anomalies in the adjacent water areas. In all latitudinal zones near the western coastal part of the subarctic zone, the phase of stable warming was expressed after 2003, and in the eastern part it has started a decade later and continues to the present. So, in 2019, the anomalies of both the mean annual $T_{a}$ and SST in the northeastern subarctic zone simultaneously increased to $1-1.5^{\circ} \mathrm{C}$, which is associated with the $P D O$ transition from a negative to a neutral phase, the subarctic circulation expansion and the Aleutian depression deepening, as well as the spread of the so-called "sea heat waves" and warming in the lower troposphere [6, 39, 40]. This year was the warmest on record in the AA region.

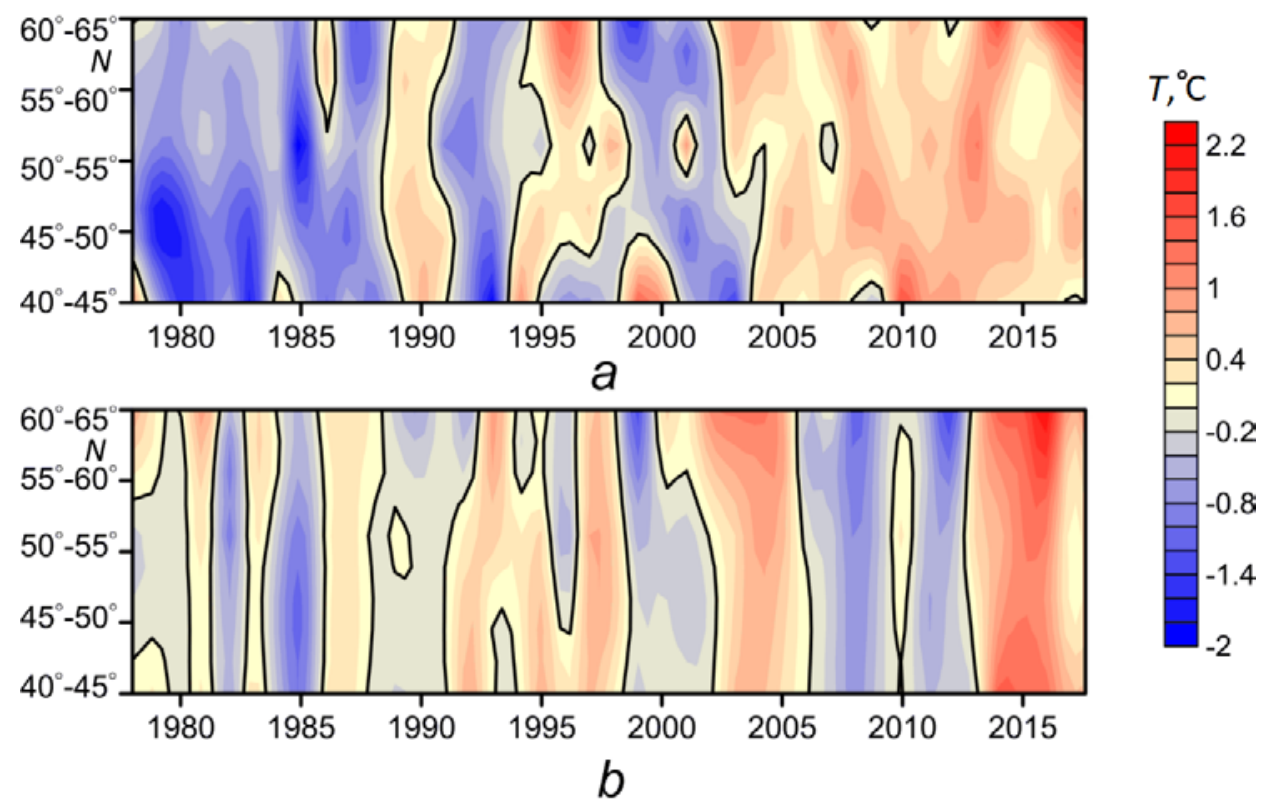

F i g. 3. Dynamics of interannual variability of the annual average air temperature anomalies $\Delta T_{a c}{ }^{\circ} \mathrm{C}$ in the coastal zone of the Pacific subarctic to the west $(a)$ and to the east $(b)$ of the meridian $170^{\circ} \mathrm{W}$

To obtain generalized data on the spatial and temporal changes in the air temperature field in the subarctic zone, the EOF of interannual oscillations of $T_{a}$ anomalies were calculated. The main EOF components provide the most comprehensive view of the main modes of large-scale interannual variability of the temperature field in the studied region. Its features can be estimated from the variance, trends and connectivity of oscillations in the spatial coordinate system. The first three modes describe $81 \%$ of the contribution of oscillations in the mean annual $\Delta T_{a}$ values to the total variance. During the warm period of the year, in the course of changes in the expansion coefficients $(\mathrm{K})$ of the first $\left(\mathrm{C}_{1}\right)$ and second $\left(\mathrm{C}_{2}\right)$ EOF modes, a significant positive trend is expressed. In the spatial distribution of the first mode, the maximal $\mathrm{C}_{1}$ values are observed in the area of the greatest trends in the annual mean $\Delta T_{a}$ values (WBS region), and 
the configuration of the second mode distribution forms a dipole with centers in the AA and TD regions (Fig. 1). During the warm period of the year, interannual changes in these modes are associated with significant correlation coefficients with air temperature oscillations both in different subarctic regions and throughout the Northern Hemisphere (authors' estimates based on NCEP/NCAR Reanalysis-1 data), as well as with other climatic variables and indicators.

\section{Correlation between thermal conditions and atmospheric processes}

To determine the cause-and-effect relationships of the formation of stable $T_{a}$ anomaly regions, a cross-correlation analysis of the $\Delta T_{a}$ time series and oscillations of the mean monthly anomalies of the geopotential field of the $500 \mathrm{hPa}$ isobaric surface, the zonal $(U)$ and meridional $(V)$ components of the wind speed, latent and sensible heat fluxes were carried out and climatic indices characterizing the state and climate system dynamics in the Pacific subarctic zone. In the interannual variability of the wind regime characteristics over the past four decades, the following trends are observed. In the northeastern part (AA region), statistically significant trends in the weakening of the southern winds were observed both in the warm (by $0.4 \mathrm{~m} / \mathrm{s}$ ) and in the cold (by $0.8 \mathrm{~m} / \mathrm{s}$ ) seasons, while in the western part (WSA area) - significant trends in the weakening of the northern winds (by $1.1 \mathrm{~m} / \mathrm{s}$ ) in the cold season, up to a change in direction to the opposite after 2017 in most of this area. Similar changes took place against the background of the Aleutian depression weakening [22, 23]. In all the regions identified, significant correlations between the oscillations of $T_{a}$ and the wind speed components, mainly in the cold period, are traced (Table 2).

Differences in the warming nature in separate regions are largely determined by the values of advective transfer of sensible $(S H)$ and latent $(L E)$ condensation heat from low latitudes to high ones and zonal transport [19, 29]. In the southwest, the study area is bordered by the energy-active zone of the ocean and atmosphere (EAZO) Kuroshio - Oyashio, which is a powerful accumulator and a source of heat to the adjacent areas [16, 19, 41]. The main routes of typhoon movement pass through this region, and cyclonic activity in the northwestern Pacific Ocean affects the thermal regime characteristics, atmospheric and oceanic circulation of the entire subarctic zone [15, 17-19]. According to https://www.esrl.noaa.gov/psd/, in $20-40^{\circ} \mathrm{N}, 125-150^{\circ} \mathrm{E}$ region from the end of the 1970 s there were stable positive trends of an increase in the average annual $L E$ and $S H$ fluxes into the atmosphere by about $4-6 \mathrm{~W} / \mathrm{m}^{-2}$ for 10 years and $2-3 \mathrm{~W} / \mathrm{m}^{-2}$ for 10 years, respectively, and an increase in the speed of southern winds during the summer monsoon by $0.8 \mathrm{~m} / \mathrm{s}$, accompanied by a decrease in the heat content of the upper 700 -meter layer $[6,13]$. In the troposphere over the same area, the maximum zonal eastern wind speeds are noted [19]. Interannual changes in heat fluxes in the EAZO and air temperature in different subarctic regions are characterized by moderate positive correlations. In the cold season in the east of the subarctic, these relations are not manifested (Table 2). 


\section{Correlation coefficients $(R)$ of the air temperature oscillations $\left(T_{a}\right)$ with the wind speed $V$-and $U$-components and the heat flux values on the ocean surface during the warm and cold seasons 1978-2018}

\begin{tabular}{|c|c|c|c|c|}
\hline Year period & $R\left(T_{a} / V\right)$ & $R\left(T_{a} / U\right)$ & $R\left(T_{a} / L E\right)$ & $R\left(T_{a} / S H\right)$ \\
\hline \multicolumn{5}{|c|}{ WBS } \\
\hline Warm & 0.2 & 0.1 & 0.5 & 0.6 \\
\hline Cold & 0.6 & -0.1 & 0.3 & 0.3 \\
\hline \multicolumn{5}{|c|}{ AA } \\
\hline Warm & -0.3 & 0.0 & 0.4 & 0.4 \\
\hline Cold & 0.4 & $-0,5$ & 0.1 & 0.1 \\
\hline \multicolumn{5}{|c|}{ WSA } \\
\hline Warm & 0.6 & 0.4 & 0.4 & 0.5 \\
\hline Cold & 0.6 & -0.1 & 0.4 & 0.3 \\
\hline \multicolumn{5}{|c|}{ TD } \\
\hline Warm & 0.3 & 0.1 & 0.5 & 0.5 \\
\hline Cold & 0.3 & -0.7 & 0.3 & 0.4 \\
\hline \multicolumn{5}{|c|}{ ESA } \\
\hline Warm & -0.2 & -0.3 & 0.4 & 0.4 \\
\hline Cold & 0.5 & -0.3 & 0.0 & 0.0 \\
\hline \multicolumn{5}{|c|}{ CR } \\
\hline Warm & 0.0 & 0.1 & 0.4 & 0.3 \\
\hline Cold & 0.4 & -0.6 & -0.1 & 0.2 \\
\hline
\end{tabular}

$\mathrm{N}$ o t e. $L E$ and $S H$ are the latent and sensible heat fluxes for the region $20-40^{\circ} \mathrm{N}, 125-150^{\circ} \mathrm{E}$.

The revealed trends and relationships reflect the regional features of the atmospheric circulation and thermal regime, the interannual changes of which are the result of the interaction of a large number of different-scale processes in the sea and the atmosphere. In the middle troposphere, at the AT-500 level, both zonal and meridional flows are significantly enhanced in comparison with surface ones [9]. During the temporal expansion coefficients of the first and third EOF modes of the geopotential anomalies $\left(\Delta H_{500}\right)$ (the entire northern Pacific Ocean was considered), statistically significant positive trends were present. Spatial distribution of the first mode coefficients $\left(\mathrm{C}_{1}\right)$ in the warm season characterizes the in-phase oscillations of the geopotential anomalies within the entire water area with a maximum (as for the $\Delta T_{a}$ trends) in the WBS region, where the value of the $\mathrm{H} 500$ trend was 1.4 dam/10 years. In the cold season, two centers of antiphase oscillations are distinguished in the $\mathrm{C}_{1}$ distribution, forming a dipole with centers near the Hawaiian and Aleutian Islands, which roughly coincide with the AAC position corresponding to their names.

Oscillations of individual $\Delta H_{500}$ and $\Delta T_{a}$ EOF modes are related both to each other (Table 3 ) and to variations in different characteristics of atmospheric circulation and the state of the ocean, expressed in terms of regional climatic indices. In the period under consideration, during the interannual oscillations of the CI majority, statistically significant trend components were present. Relation with them reflects the influence of various large-scale processes on 158 
the structure of pressure and wind fields and thermal characteristics [22]. In the subarctic zone, the impact of these processes is most pronounced through the correlations of individual CIs ( $P D O, N P, S O I, A D, A M O$ and $K_{1}$ EOF $\Delta H_{500}$ ) with the main modes of air temperature variability in the study area (Table 3 ).

Table 3

Correlation coefficients of interannual oscillations of the climatic indices (CI) and $K_{1}$ EOF $\Delta H_{500}$ with variations of the first modes EOF $\Delta T_{a}$ coefficients in the warm (w) and cold (c) seasons for 1978-2018

\begin{tabular}{l|cc|c|c|c|c|c|c|c|c}
\hline \multirow{2}{*}{ Parameters } & \multicolumn{2}{|c|}{$P D O$} & $N P^{*}$ & \multicolumn{2}{c|}{$S O I$} & $A D$ & $P T W$ & $A M O$ & \multicolumn{2}{c}{$K_{1} \Delta H_{500}$} \\
\cline { 2 - 11 } & $\mathrm{T} / \mathrm{w}$ & $\mathrm{x} / \mathrm{c}$ & $\mathrm{x} / \mathrm{c}$ & $\mathrm{T} / \mathrm{w}$ & $\mathrm{x} / \mathrm{c}$ & $\mathrm{T} / \mathrm{w}$ & $\mathrm{T} / \mathrm{w}$ & $\mathrm{T} / \mathrm{w}$ & $\mathrm{T} / \mathrm{w}$ & $\mathrm{x} / \mathrm{c}$ \\
\hline$b(C I)$ & $\mathbf{- 0 . 2}$ & -0.1 & $\mathbf{0 . 6}$ & 0.1 & $\mathbf{0 . 4}$ & -0.1 & $\mathbf{0 . 5}$ & $\mathbf{0 . 1}$ & $\mathbf{0 . 6}$ & $\mathbf{0 . 4}$ \\
\hline$K_{1} \Delta T_{a}$ & 0.1 & $\mathbf{0 . 5}$ & -0.1 & 0.0 & -0.1 & 0.1 & 0.0 & $\mathbf{0 . 4}$ & $\mathbf{0 . 6}$ & 0.2 \\
\hline$K_{2} \Delta T_{a}$ & $\mathbf{- 0 . 9}$ & $\mathbf{0 . 6}$ & $\mathbf{- 0 . 7}$ & $\mathbf{0 . 4}$ & $\mathbf{- 0 . 5}$ & $\mathbf{- 0 . 7}$ & $\mathbf{0 . 5}$ & $\mathbf{0 . 3}$ & $\mathbf{0 . 3}$ & $\mathbf{- 0 . 7}$ \\
\hline
\end{tabular}

$\mathrm{N}$ o t e: $b(C I)$ is the slope coefficient of the linear trend, conv. units/10 years.

* Based on the updated data.
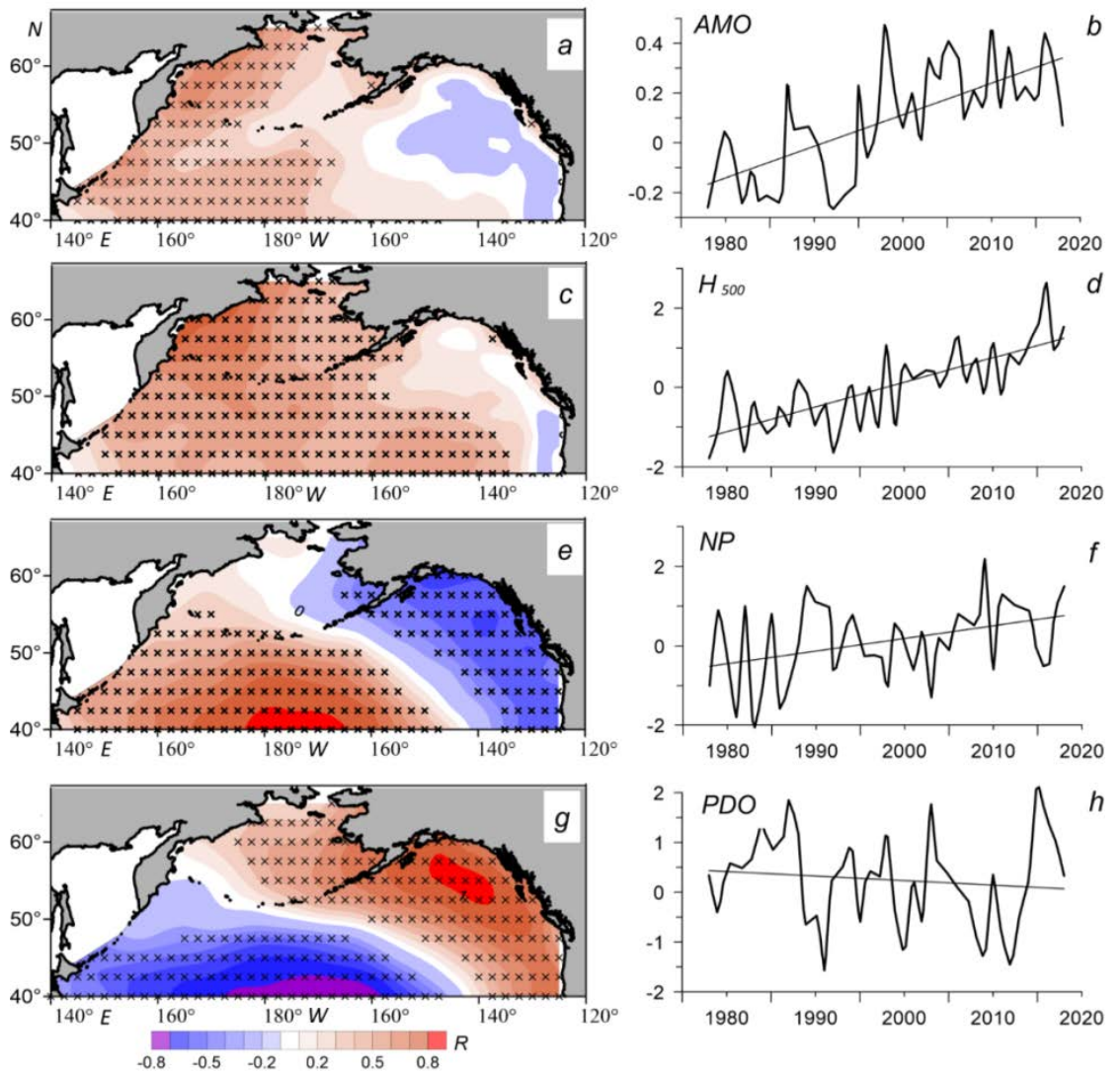

F i g. 4. Correlation coefficients $(R)$ of the air temperature oscillations, the climatic indices $A M O(a)$, $N P(e), P D O(g)$ variations and the first mode $\mathrm{C}_{1}\left(\Delta \mathrm{H}_{500}\right)(c)$; the interannual changes of these parameters in warm $(b, d)$ and cold $(f, h)$ periods of a year. Crosses denote the grid points in which $R$ are statistically significant at the $95 \%$ level 
Nature of the corresponding relationships is expressed in the field of isocorrelates - the spatial distribution of the correlation coefficients of various indices with $T_{a}$ (Fig. 4). The features of this field reflect the main features of the spatial distribution of the first (Fig. 4, $a, c$ ) and second (Fig. 4, e,g) $\Delta T_{a}$ EOF modes.

Moderate correlations, reflecting local and seasonal features of the isocorrelate fields, are also expressed with the following CIs: West Pacific (WP), Pacific/ North American (PNA) and East Pacific / North Pacific (EP/NP). There are no statistically significant correlations of the considered CIs with the coefficients of the third $\Delta T_{a}$ EOF mode, which describes $9 \%$ of the total dispersion of the temperature field. In the warm period of the year, such relations are manifested with the third mode oscillations of the geopotential field anomalies $(R=0.5)$, in the cold period - with the oscillation index of the North Pacific Gyre (NPGO http://www.oces.us/npgo/) $(R=-0.4)$.

In the presence of a close correlation between air temperature oscillations and SST, the noted features of changes in these climatic parameters are in good agreement with each other, and the analysis of the corresponding changes in the underlying layers of the water column requires separate consideration. A preliminary analysis of the available data showed that changes in water temperature and anomalies in heat content in the water column of the regions under study are extremely uneven, which is associated with the peculiarities of the atmosphere and ocean circulation and is a consequence of the heat redistribution between individual layers of the water column and different regions by horizontal advection.

\section{Conclusion}

Global warming trends at the turn of $20-21^{\text {st }}$ centuries are expressed in trends (b) of interannual variability of surface air temperature and other climatic characteristics. Their value indicates significant regional differences in the ongoing changes. For example, in the west of the Pacific subarctic zone, the warming rate is much higher than in the east, where temperature trends are either minimal or statistically insignificant. In the northwestern Bering Sea, both according to observations at the MS and according to the reanalysis, the highest $b$ values $\left(0.6^{\circ} \mathrm{C} / 10\right.$ years and $0.9^{\circ} \mathrm{C} / 10$ years, respectively) are noted, comparable with the estimates for the eastern Arctic sector seas over the same period. In all latitudinal zones near the western subarctic coast, the phase of stable warming was expressed after 2003, in the eastern part - only a decade later. By 2019 in the northeastern part of the region, the mean annual $T_{a}$ anomalies reached their maximum over the entire history of observations. Within the marine areas of the southern subarctic, the warming trends corresponded to a moderate increase in $T_{a}$ by $0.1-0.3^{\circ} \mathrm{C}$ per decade, and the value of the mean annual $T_{a}$ trend over the entire Pacific subarctic water area is estimated at $0.20^{\circ} \mathrm{C} / 10$ years. As a rule, in the warm season, this value is higher than in the cold one.

In all the regions selected, mainly in the cold season, positive correlations between an increase in $T_{a}$ and fluctuations in the meridional component of the wind speed are clearly manifested, and the weakening of the northern winds and 
the strengthening of the southern ones during this period are accompanied by warming over the ocean.

Differences in the nature of warming in certain regions of the subarctic zone are largely influenced by the advective transfer of sensible and latent heat from the EAZO Kuroshio - Oyashio, which is a powerful accumulator and source of heat for adjacent regions. Since the late 1970s there steady positive trends of an increase in these flows, contributing to an increase in cyclonic activity and general warming in the subarctic have been observed there.

Separate phases of alternation of warm and cold periods in the interannual variation of $T_{a}$ are consistent with the trends in the pressure field, the AAC characteristics and climatic indices. This relation indicates the strengthening or weakening of the influence of various large-scale processes on the thermal conditions of the region in different seasons of the year. In the subarctic zone, the impact of these processes is most pronounced through the correlations of individual CIs ( $P D O, N P, S O I, A D, A M O$ and $K_{1}$ EOF $\left.\Delta H_{500}\right)$ with the main modes of air temperature variability in the study area.

\section{References}

1. Gruza, G.V., Rankova, E.Ya., Rocheva, E.V. and Smirnov, V.D., 2015. Current Global Warming: Geographical and Seasonal Features. Fundamental and Applied Climatology, 2, pp. 41-62 (in Russian).

2. Panin, G.N., Vyruchalkina, T.Yu. and Solomonova, I.V., 2010. Regional Climatic Changes in Northern Hemisphere and Their Relationship to Circulation Indexes. Problems of Ecological Monitoring and Ecosystem Modelling, 23, pp. 92-108 (in Russian).

3. England, M.H., McGregor, S., Spence, P., Meehl, G.A., Timmermann, A., Cai, W., Gupta, A.S., McPhaden, M.J., Purich, A. and Santoso, A., 2014. Recent Intensification of Wind-Driven Circulation in The Pacific and the Ongoing Warming Hiatus. Nature Climate Change, 4(3), pp. 222-227. https://doi.org/10.1038/nclimate2106

4. IPCC, 2013. Climate Change 2013: The Physical Science Basis. Contribution of Working Group I to the Fifth Assessment Report of the Intergovernmental Panel on Climate Change. Cambridge, United Kingdom and New York, NY, USA: Cambridge University Press, $1535 \mathrm{pp}$.

5. WMO, 2020. WMO Provisional Statement on The State of The Global Climate in 2019. WMO-No. 1248. 40 p. https://library.wmo.int/doc_num.php?explnum_id=10211

6. Blunden, J. and Arndt, D.S., 2020. State of the Climate in 2019. Bulletin of the American Meteorological Society, $\quad$ 101(8), $\quad$ pp. https://doi.org/10.1175/2020BAMSStateoftheClimate.1

7. Miller, A.J., Chai, F., Chiba, S., Moisan, J.R. and Neilson, D.J., 2004. Decadal-Scale Climate and Ecosystem Interactions in the North Pacific Ocean. Journal of Oceanography, 60(1), pp. 163-188. doi:10.1023/B:JOCE.0000038325.36306.95

8. Hare, S.R. and Mantua, N.J., 2000. Empirical Evidence for North Pacific Regime Shifts in 1977 and 1989. Progress in Oceanography, 47(2-4), pp. 103-145. doi:10.1016/S00796611(00)00033-1

9. Perevedentsev, Yu.P. and Shantalinskiy, K.M., 2015. Dynamics of the Tropo- and Stratosphere and the Modern Climate Changes. Fundamental and Applied Climatology, 1, pp. 211-231 (in Russian).

10. Steiner, A.K., Ladstädter, F., Randel, W.J., Maycock, A.C., Fu, Q., Claud, C., Gleisner, H., Haimberger, L., Ho, S.-P., Keckhut, P., Leblanc, T., Mears, C., Polvani, L.M., Santer, B.D., Schmidt, T., Sofieva, V., Wing, R. and Zou, C.-Z., 2020. Observed Temperature Changes in the Troposphere and Stratosphere from 1979 to 2018. Journal of Climate, 33(19), pp. 81658194. https://doi.org/10.1175/JCLI-D-19-0998.1 
11. Na, H., Kim, K.-Y., Minobe, S. and Sasaki, Y.N., 2018. Interannual to Decadal Variability of the Upper-Ocean Heat Content in the Western North Pacific and Its Relationship to Oceanic and Atmospheric Variability. Journal of Climate, 31(13), pp. 5107-5125. https://doi.org/10.1175/JCLI-D-17-0506.1

12. Johnson, N.C. and Feldstein, S.B., 2010. The Continuum of North Pacific Sea Level Pressure Patterns: Intraseasonal, Interannual, and Interdecadal Variability. Journal of Climate, 23(4), pp. 851-867. doi:10.1175/2009JCLI3099.1

13. Johnson, G.C. and Lyman, J.M., 2020. Warming Trends Increasingly Dominate Global Ocean. Nature Climate Change, 10(8), pp. 757-761. https://doi.org/10.1038/s41558-0200822-0

14. Stephens, C., Levitus, S., Antonov, J. and Boyer, T.P., 2001. On the Pacific Ocean Regime Shift. Geophysical Research Letters, 28(19), pp. 3721-3724. https://doi.org/10.1029/2000GL012813

15. Kwon, Y.-O., Alexander, M.A., Bond, N.A., Frankignoul, C., Nakamura, H., Qiu, B. and Thompson, L.A., 2010. Role of the Gulf Stream and Kuroshio-Oyashio Systems in LargeScale Atmosphere-Ocean Interaction: A Review. Journal of Climate, 23(12), pp. 3249-3281. doi:10.1175/2010JCLI3343.1

16. Rojdestvensky, A.E. and Malyshev, G.A., 2016. About Sources and Absorbers Atmospheric Heat Flux in the North Hemisphere. Proceedings of the Russian State Hydrometeorological University, 45, pp. 142-150 (in Russian).

17. Glebova, S.Yu., 2018. Cyclones over the Pacific Ocean and Far-Eastern Seas in Cold and Warm Seasons and Their Influence on Wind and Thermal Regime in the Last Two Decade Period. Izvestiya TINRO, 193, pp. 153-166. doi:10.26428/1606-9919-2018-193-153-166 (in Russian)

18. O'Reilly, C.H. and Czaja, A., 2015. The Response of the Pacific Storm Track and Atmospheric Circulation to Kuroshio Extension Variability. Quarterly Journal of the Royal Meteorological Society, 141(686), pp. 52-66. https://doi.org/10.1002/qj.2334

19. Huang, J., Zhang, Y., Yang, X.-Q., Ren, X. and Hu, H., 2020. Impacts of North Pacific Subtropical and Subarctic Oceanic Frontal Zones on the Wintertime Atmospheric Large-Scale Circulations. Journal of Climate, 33(5), pp. 1897-1914. https://doi.org/10.1175/JCLI-D-190308.1

20. Lee, T., Fukumori, I. and Tang, B., 2004. Temperature Advection: Internal versus External Processes. Journal of Physical Oceanography, 34(8), pp. 1936-1944. https://doi.org/10.1175/1520-0485(2004)034<1936:TAIVEP>2.0.CO;2

21. Rostov, I.D., Dmitrieva, E.V., Rudykh, N.I. and Vorontsov, A.A., 2019. Climatic Changes of Thermal Condition in the Kara Sea at Last 40 Years. Arctic and Antarctic Research, 65(2), pp. 125147. doi:10.30758/0555-2648-2019-65-2-125-147 (in Russian).

22. Rostov, I.D., Dmitrieva, E.V., Rudykh, N.I. and Vorontsov, A.A., 2020. Climatic Changes in Thermal Conditions of Marginal Seas in the Western Pacific. Russian Meteorology and Hydrology, 45(3), pp. 169-178. doi:10.3103/S1068373920030048

23. Sun, C., Kucharski, F., Li, J., Wang, K., Kang, I.-S., Lian, T., Ding, R. and Xie, F., 2019. Spring Aleutian Low Weakening and Surface Cooling Trend in Northwest North America during Recent Decades. Journal of Geophysical Research: Atmospheres, 124(22), pp. 1207812092. https://doi.org/10.1029/2019JD031405

24. Dobrovolski, A.D., ed., 1968. [Pacific Ocean. Vol. 2. Hydrology of the Pacific Ocean]. Moscow: Nauka, 524 p. (in Russian).

25. Favorite, F., Dodimead, A.J. and Nasu, K., 1976. Oceanography of the Subarctic Pacific Region, 1960-1971. Bulletin - International North Pacific Fisheries Commission, no. 33. Vancouver, Canada, 187 p.

26. Furtado, J.C., Di Lorenzo, E., Anderson, B.T. and Schneider, N., 2012. Linkages between the North Pacific Oscillation and Central Tropical Pacific SSTs at Low Frequencies. Climate Dynamics, 39(12), pp. 2833-2846. doi:10.1007/s00382-011-1245-4 
27. Wu, C.-R., Lin, Y.-F., Wang, Y.-L., Keenlyside, N. and Yu, J.-Y., 2019. An Atlantic-Driven Rapid Circulation Change in the North Pacific Ocean during the Late 1990s. Scientific Reports, 9, 14411. https://doi.org/10.1038/s41598-019-51076-1

28. Wills, R.C.J., Battisti, D.S., Proistosescu, C., Thompson, L.-A., Hartmann, D.L. and Armour, K.C., 2019. Ocean Circulation Signatures of North Pacific Decadal Variability. Geophysical Research Letters, 46(3), pp. 1690-1701. https://doi.org/10.1029/2018GL080716

29. Cayan, D.R., 1992. Latent and Sensible Heat Flux Anomalies over the Northern Oceans: Driving the Sea Surface Temperature. Journal of Physical Oceanography, 22(8), pp. 859-881. https://doi.org/10.1175/1520-0485(1992)022<0859:LASHFA>2.0.CO;2

30. Honda, M., Yamane, S. and Nakamura, H., 2007. Inter-Basin Link between the North Pacific and North Atlantic in the Upper Tropospheric Circulation: Its Dominance and Seasonal Dependence. Journal of the Meteorological Society of Japan. Ser. II, 85(6), pp. 899-908. doi:10.2151/jmsj.85.899

31. Wu, L., Liu, Z., Liu, Y., Liu, Q., and Liu, X., 2005. Potential Global Climatic Impacts of the North Pacific Ocean. Geophysical Research Letters, 32(24), 224710. doi:10.1029/2005GL024812

32. Kalnay, E., Kanamitsu, M., Kistler, R., Collins, W., Deaven, D., Gandin, L., Iredell, M., Saha, S., White, G., Woollen, J., Zhu, Y., Chelliah, M., Ebisuzaki, W., Higgins, W., Janowiak, J., Mo, K.C., Ropelewski, C., Wang, J., Leetmaa, A., Reynolds, R., Jenne, R. and Joseph, D., 1996. The NCEP/NCAR 40-Year Reanalysis Project. Bulletin of the American Meteorological Society, 77(3), pp. 437-472. doi:10.1175/15200477(1996)077<0437:tnyrp>2.0.co;2

33. Thomson, R.E. and Emery, W.J., 2014. Data Analysis Methods in Physical Oceanography. $3 \mathrm{r}^{\mathrm{d}}$ edition. Elsevier Science, 728 p. https://doi.org/10.1016/C2010-0-66362-0

34. Reynolds, R.W., Rayner, N.A., Smith, T.M., Stokes D.C. and Wang W., 2002. An Improved In Situ and Satellite SST Analysis for Climate. Journal of Climate, 15(13), pp. 1609-1625. doi:10.1175/1520-0442(2002)015<1609:AIISAS>2.0.CO;2

35. Frankignoul, C. and Sennéchael, N., 2007. Observed Influence of North Pacific SST Anomalies on the Atmospheric Circulation. Journal of Climate, 20(3), pp. 592-606. doi:10.1175/JCLI4021.1

36. Liu, Q., Wen, N. and Liu, Z., 2006. An Observational Study of the Impact of the North Pacific SST on the Atmosphere. Geophysical Research Letters, 33(18), L18611. doi:10.1029/2006GL026082

37. Deser, C., Phillips, A.S. and Hurrell, J.W., 2004. Pacific Interdecadal Climate Variability: Linkages between the Tropics and the North Pacific during Boreal Winter since 1900. Journal of Climate, 17(16), pp. 3109-3124. doi:10.1175/15200442(2004)017<3109:PICVLB>2.0.CO;2

38. Sugimoto, S. and Hanawa, K., 2009. Decadal and Interdecadal Variations of the Aleutian Low Activity and Their Relation to Upper Oceanic Variations over the North Pacific. Journal of the Meteorological Society of Japan. Ser. II, 87(4), pp. 601-614. doi:10.2151/jmsj.87.601

39. Amaya, D.J., Miller, A.J., Xie, S.-P. and Kosaka, Yu, 2020. Physical Drivers of the Summer 2019 North Pacific Marine Heatwave. Nature Communications, 11, 1903. https://doi.org/10.1038/s41467-020-15820-w

40. Di Lorenzo, E. and Mantua, N., 2016. Multi-Year Persistence of the 2014/15 North Pacific Marine Heatwave. Nature Climate Change, 6(11), pp. 1042-1047. doi:10.1038/NCLIMATE3082

41. Hu, D. and Cui, M., 1991. The Western Boundary Current of the Pacific and its Role in the Climate. Chinese Journal of Oceanology and Limnology, 9(1), pp. 1-14. doi:10.1007/BF02849784

About the authors:

Igor D. Rostov, Head of the Informatics and Ocean Monitoring Laboratory FSBSI V.I.Il'ichev Pacific Oceanological Institute, Far Eastern Branch, Russian Academy of Sciences (3 Baltiyskaya Street, 
Vladivostok, 690041, Russian Federation), PhD (Geogr.), , ORCID ID: 0000-0001-5081-7279, rostov@poi.dvo.ru

Elena V. Dmitrieva, Senior Research Associate, Informatics and Ocean Monitoring Laboratory FSBSI V.I.Il'ichev Pacific Oceanological Institute, Far Eastern Branch, Russian Academy of Sciences (3 Baltiyskaya Street, Vladivostok, 690041, Russian Federation), PhD (Techn. Sci.), ORCID ID: 0000-0002-0094-5296, e_dmitrieva@poi.dvo.ru

Natalya I. Rudykh, Senior Research Associate, Informatics and Ocean Monitoring Laboratory FSBSI V.I.Il'ichev Pacific Oceanological Institute, Far Eastern Branch, Russian Academy of Sciences (3 Baltiyskaya Street, Vladivostok, 690041, Russian Federation), PhD (Geogr.), ResearcherID: N-5821-2018, rudykh@poi.dvo.ru

Contribution of the co-authors:

Igor D. Rostov - development of the article structure, processing and analysis of the data, writing the article text

Elena V. Dmitrieva - collection and preparation of initial data for reanalysis, calculations, drawing design, text editing

Natalya I. Rudykh - collection and processing of initial data on meteorological stations, calculations, editing of text and references

All the authors have read and approved the final manuscript.

The authors declare that they have no conflict of interest. 